(2) Open Access Full Text Article

ORIGINAL RESEARCH

\title{
Repurposing Disulfiram as an Anti-Obesity Drug: Treating and Preventing Obesity in High-Fat-Fed Rats
}

This article was published in the following Dove Press journal: Diabetes, Metabolic Syndrome and Obesity: Targets and Therapy

\author{
Ziad Omran' \\ Ryan Sheikh (iD) ${ }^{2}$ \\ Othman A Baothman (iD ${ }^{2}$ \\ Mazin A Zamzami ${ }^{2}$ \\ Mohamed Alarjah' \\ 'College of Pharmacy, Umm Al-Qura \\ University, Makkah 21955, Kingdom of \\ Saudi Arabia; ${ }^{2}$ Biochemistry Department, \\ Faculty of Science, King Abdulaziz \\ University, Jeddah, Kingdom of Saudi \\ Arabia
}

Background and Objectives: A drug repurposing strategy is an approach for identifying new therapeutic uses for approved or investigational drugs. Thanks to the moderate cost of repurposing a drug compared to bringing new chemical entity to the market, drug repurposing is rapidly gaining ground. The aim of this work is to study the anti-obesity effect of disulfiram (DSF), an irreversible aldehyde dehydrogenase inhibitor approved by the Food and Drug Administration (FDA) to treat chronic alcoholism since 1951.

Methods: Thirty male Albino rats were randomly assigned to six groups. G1, the control group, was given a standard diet. G2, the positive control group, was given a high-fat diet (HFD). G3 was given an HFD, and DSF $50 \mathrm{mg} / \mathrm{kg}$ /day was administered orally from day one for six weeks. G4 was given an HFD, and DSF $200 \mathrm{mg} / \mathrm{kg} / \mathrm{day}$ was administered orally from day one for six weeks. G5 was given an HFD for six weeks; then treatment started with $50 \mathrm{mg} / \mathrm{kg}$ /day DSF orally. G6 was given an HFD for six weeks; then treatment started with $200 \mathrm{mg} / \mathrm{kg} /$ day DSF orally for three weeks. The body weight, food consumption and blood glucose levels were monitored over the given time interval.

Results: Both doses of DSF significantly limited the body weight gain caused by an HFD for the treated animals. HF-fed rats received 50 and $200 \mathrm{mg} / \mathrm{kg} /$ day of DSF had their body weight increased by $51.93 \pm 7.89 \%$ and $20.88 \pm 15.05 \%$ respectively, whereas the body weight of control animals increased by $93.1 \pm 20.04 \%$. DSF also significantly decreased the body weight of obese animals. At 50 and $200 \mathrm{mg} / \mathrm{kg} /$ day of DSF, HF-fed rats lost $16.74 \pm$ $8.61 \%$ and $23.9 \pm 3.93 \%$ respectively, as their untreated counterparts had their body weight increased by $11.85 \pm 3.79 \%$ after three weeks of treatment, thus restoring a body weight matching those who received a standard diet.

Conclusion: FDA-approved disulfiram has a strong anti-obesity effect on HFD-fed rats.

Keywords: obesity, drug repurposing, Aldh1a1, disulfiram

\section{Introduction}

The pandemic of obesity is growing at a worrying pace, with an estimated direct and indirect cost of US $\$ 150$ billion per year in the US alone. ${ }^{1}$ Recent studies suggest that one out of five deaths is linked in one way or another to obesity. ${ }^{1}$ Since 1975 , the obesity prevalence has almost tripled. ${ }^{2}$ Obesity is a main risk factor for many serious diseases, such as type II diabetes, fatty liver, cardiovascular diseases and cancer, among others. ${ }^{3,4}$ Additionally, obesity has important psychological impacts on patients, resulting in a lower quality of life. ${ }^{5}$ Although obesity is recognized by the World Health Organization as one of the major challenges in
Correspondence: Ziad Omran

College of Pharmacy, Umm Al-Qura

University, Al-Abidiyya, Makkah 21955,

Kingdom of Saudi Arabia

Tel +9665 4646I44I

Email zhomran@uqu.edu.sa 
public health in the twenty-first century, ${ }^{2}$ there is still no clear-cut solution. ${ }^{6}$ To date, the Food and Drug Administration (FDA) has approved only five drugs or drug combinations for long-term obesity treatment: orlistat, lorcaserin, liraglutide, bupropion-naltrexone and phentermine-topiramate. ${ }^{7}$ Four other drugs are FDAapproved for short-term use: benzphetamine, phentermine, phendimetrazine and diethylpropion. ${ }^{7}$ Very recently, lorcaserin was withdrawn from the US market, as a safety clinical trial showed an increased occurrence of cancer. ${ }^{8}$ Meanwhile, the European Medicines Agency has approved only three medicines, orlistat, bupropion-naltrexone and liraglutide, for obesity management in the European Union. ${ }^{9}$ Thus, developing new pharmacotherapies to treat obesity is of imminent importance to fulfill a highly unmet medical need.

A drug repurposing strategy, also called repositioning, is an approach for identifying new therapeutic uses for approved or investigational drugs. ${ }^{10}$ These new uses are usually outside the original medical indication. ${ }^{11}$ Because of the high attrition rate, escalating costs and long timeframes for new drug discovery, drug repurposing is rapidly gaining ground. ${ }^{10}$ The average cost of a successful drug repurposing is estimated to be US $\$ 300$ million, about a tenth of that of bringing a new chemical entity to the market. ${ }^{12}$ Since the repurposed drug successfully passed the safety assessment in preclinical studies and clinical trials, the risk of failure is significantly lower. ${ }^{10}$ The redirection of sildenafil, which was originally developed as an antihypertensive agent to treat erectile dysfunction, is a great example of successful drug repurposing. The approval of thalidomide in 2006 to treat multiple myeloma is yet another example. ${ }^{10}$ Drug repurposing could also be a useful approach during outbreaks of emerging diseases such as the recent attempts to use the FDA-approved human immunodeficiency virus (HIV) type 1 aspartate protease inhibitor, lopinavir, ${ }^{13}$ or the combination of the anti-malaria agent hydroxychloroquine with the macrolide antibiotic azithromycin to overcome the current pandemic of coronavirus disease 2019 (COVID-19). ${ }^{14}$

Disulfiram (DSF), Figure 1, is an irreversible aldehyde dehydrogenase inhibitor. Disulfiram blocks the alcohol metabolism at the acetaldehyde stage, leading to the accumulation of the latter in the blood. This in turn produces a highly unpleasant reaction, which includes low blood pressure, tachycardia, facial flushing, vomiting and vertigo when the patient treated with disulfiram ingests even small amounts of alcohol. ${ }^{15}$ In 1951, disulfiram was the first drug

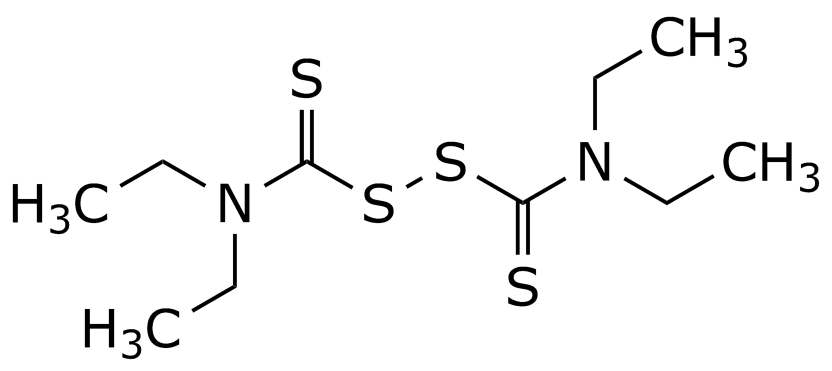

Figure I Chemical structure of disulfiram.

to be approved by the FDA to treat chronic alcoholism. Many studies since then have shown the potential of repurposing disulfiram as an anticancer agent. ${ }^{16}$ Currently, disulfiram is progressing through different stages of clinical trials to treat diverse types of malignant tumors, such as metastatic breast cancer, glioblastoma and recurrent pancreatic carcinoma. Disulfiram has also shown therapeutic potential as a latency-reversing agent in treating AIDS patients. ${ }^{17,18}$ More recently, disulfiram was shown to be beneficial in treating Lyme disease and babesiosis. ${ }^{19}$

In addition to inhibiting Aldh2, the isoform responsible for alcohol metabolism, disulfiram even more potently inhibits Aldh1a1, ${ }^{20}$ the cytosolic isoform that irreversibly converts retinaldehyde (Rald) into retinoic acid. ${ }^{21,22}$ The expression of Aldh1a1 is significantly higher in obese patients compared to lean subjects. ${ }^{23}$ Furthermore, the disruption of expression or function of this enzyme in rats rendered them resistant to diet-induced obesity. ${ }^{24}$ Moreover, Aldh1a1 deficient adipocytes were shown not only to effectively reduce body weight of mice fed a highfat diet (HFD), ${ }^{25,26}$ but also they markedly reduced waist circumference, body weight, and fat mass when implanted into visceral fat depots of obese large animal models such as dogs. ${ }^{27}$ Additionally, Aldh1a1-deficient mice are viable and do not show any growth or survival defects. ${ }^{28}$

Thus, inhibiting the function of Aldh1a1 is clearly an attractive approach to treating obesity. In this study, we showed that disulfiram can not only effectively reduce the body weight of obese rats but that it also prevents weight gain induced by an HFD in rats.

\section{Materials and Methods}

\section{Diet}

Standard diet (SD) was purchased from Grains Silos \& Flour Mills Organization, SA, Item No. F1005. SD is composed of $20 \%$ protein, $4 \%$ fat and $50 \%$ carbohydrates. 
The high-fat diet was prepared weekly in the lab according to the following prescription: $40 \%$ cow fat, $10 \%$ eggs, $10 \%$ sugar and $40 \%$ standard diet.

\section{Animal Experiments}

Thirty male Albino rats $(210 \pm 20 \mathrm{~g})$ were purchased from the King Fahad Medical Research Center, Jeddah, KSA. The rats were kept at $25 \pm 2{ }^{\circ} \mathrm{C}$ in a $12 \mathrm{~h}$ light-and-dark cycle condition for five days' acclimation. Then the rats (8 weeks of age) were divided randomly into six groups (G1G6) of five animals:

G1: Control group: was given a standard diet (SD).

G2 and G5: Positive control group: was given a highfat diet (HFD).

G3: was given high a fat-diet, and DSF $50 \mathrm{mg} / \mathrm{kg} /$ day was administered orally from day one for six weeks.

G4: was given an HFD, and DSF $200 \mathrm{mg} / \mathrm{kg} /$ day was administered orally from day one for six weeks.

G6: was given an HFD for six weeks; then treatment started with $50 \mathrm{mg} / \mathrm{kg} /$ day DSF orally.

G7: was given a high-fat diet for six weeks; then treatment started with $200 \mathrm{mg} / \mathrm{kg} /$ day DSF orally.

All the groups had free access to water and the designated diet.

At the end of week six, HFD-fed rats were redistributed into three new groups, G5, G6 and G7 of five animals each in order to ensure a close body weight average $(415 \pm 10 \mathrm{~g})$.

All protocols were approved by the Biomedical Ethics Committee of the Faculty of Medicine, King Abdulaziz University. The experiments were carried out according the regulations of Saudi National Committee for Bioethics.

\section{Drug Administration}

Disulfiram USP was purchased from Xenex Laborotories Inc, Coquitlam, CA. Catalogue No. DI175.

The DSF dose was calculated according to the rat body weight. DSF was dispersed in vegetable oil $(1 \mathrm{~mL})$ and was given daily to the rats by gavage.

\section{Oral Glucose Tolerance Test (OGTT)}

OGTT was performed at the end of the study. The rats were made to fast for over $5 \mathrm{~h}$, and a baseline blood draw from the lateral tail vein was collected for plasma fasting glucose. The animals were gavaged with a glucose solution of $2 \mathrm{~g} / \mathrm{kg}$ body weight, and blood droplets from the tail vein were thereafter collected to measure glycemia at $30,60,90$ and 120 min. $^{29,30}$ Glucose levels were measured by Bayer Contour ${ }^{\circledR}$ TS Blood Glucose Test Strips and Bayer Contour ${ }^{\circledR}$ TS Blood Glucose Monitoring System.

\section{Statistical Analysis}

Descriptive statistics were performed for all variables. The data are expressed in mean \pm SD. Normality tests were done with a Shapiro-Wilk test for all data to check for normality.

For the primary outcome analysis, ANOVA or the Kruskal Wallis test (depending on the normality) was done to compare between all groups. Post hoc analysis was performed using either a Tukey HSD test if equal variance was assumed or a Games-Howell test if equal variances were not assumed. Paired $t$-test or Mann Whitney test (depending on the normality) was used to check for the statistical significance difference within every group. A significance level of $\mathrm{P}<0.05$ was used to detect any statistical differences. No sample was excluded from the analysis. Secondary analysis for OGTT was done using both area under the curve (AUC) and ANOVA to test and visualize the difference between different group in response to the oral glucose.

Statistical analysis was carried out using SPSS 24 (IBM SPSS Inc. Chicago, IL, USA). Graphs were created using GraphPad Prism 7 (GraphPad Software Inc., San Diego, CA, USA).

\section{Results \\ Body Weight}

Over the first six weeks of the study, using paired $t$ test we can notice that the body weight of the rats receiving a standard diet (G1) increased by $59.8 \pm 7.94 \%$ (from 200.0 $\pm 31.93 \mathrm{~g}$ to $315.6 \pm 27.15 \mathrm{~g})(P<0.001)$. But the rats on HFD (G2) gained $93.1 \pm 20.04 \%$ (from $232.6 \mathrm{~g} \pm 22.45$ to $448.0 \pm 52.03 \mathrm{~g})(P<0.001)$. Meanwhile, the body weight gain of HFD-fed rats receiving $50 \mathrm{mg} / \mathrm{kg} /$ day of DSF (G3) was only $51.93 \pm 7.89 \%$ (from $231.6 \pm 19.23 \mathrm{~g}$ to $358.8 \pm$ $33.26 \mathrm{~g})(P<0.001)$. On the other hand, a high dose of DSF, $200 \mathrm{mg} / \mathrm{kg} /$ day (G4), limited the body weight gain caused by HFD to only $20.88 \pm 15.05 \%$ (from $230.4 \pm 12.14 \mathrm{~g}$ to 279.0 $\pm 41.22 \mathrm{~g})(P=0.036)$, Figure 2.

At week six, rats fed with HFD were redistributed into three groups, G5, G6 and G7, to ensure a close body weight average. By using paired $t$ test we can notice that G5, which continued receiving HFD, had their body weight increased $11.85 \pm 3.79 \%$ (from $422.5 \pm 58.38 \mathrm{~g}$ to $473.3 \pm 78.25 \mathrm{~g}$ ) $(P=0.021)$ over a period of three weeks, whereas the body 

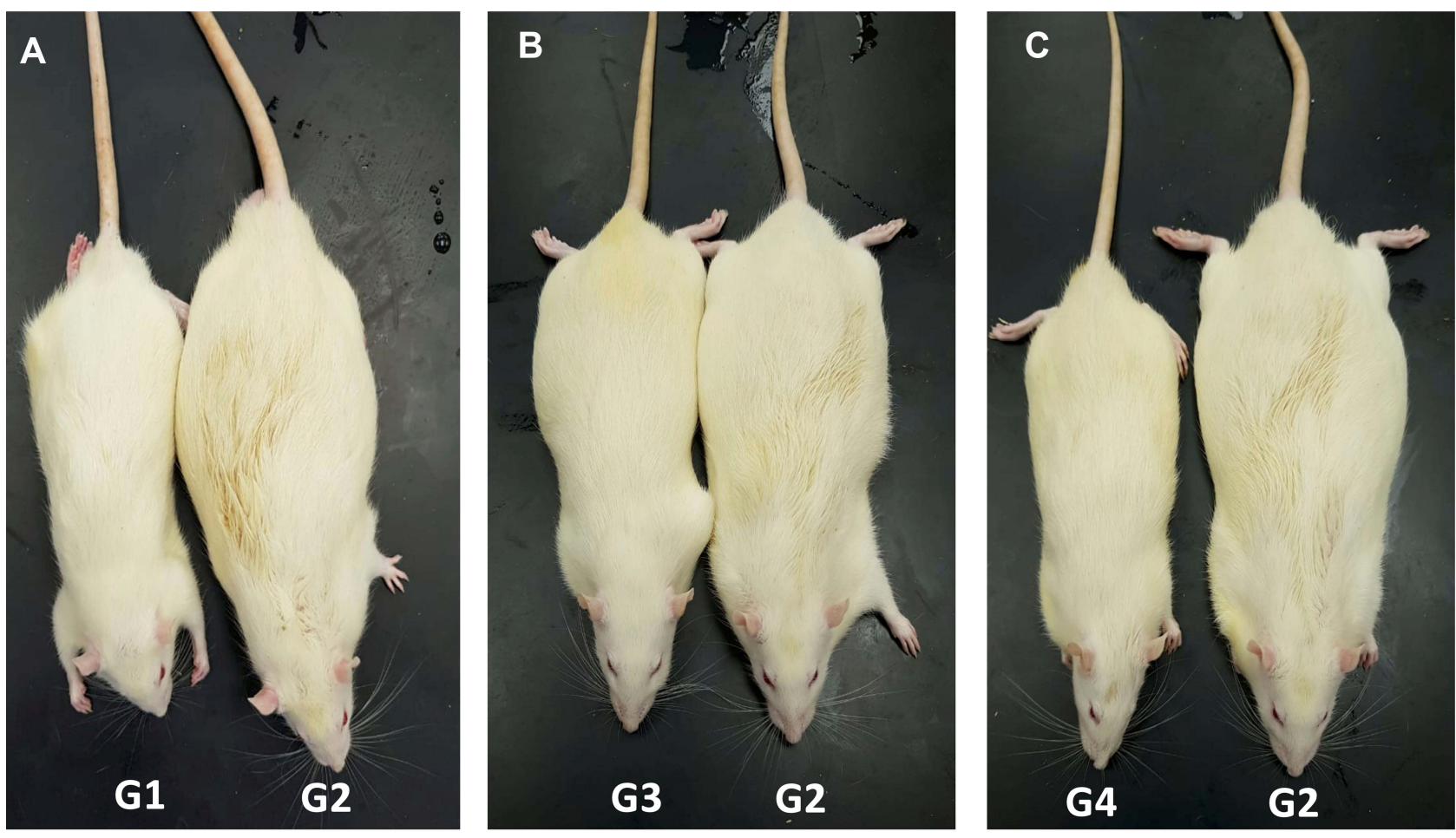

D

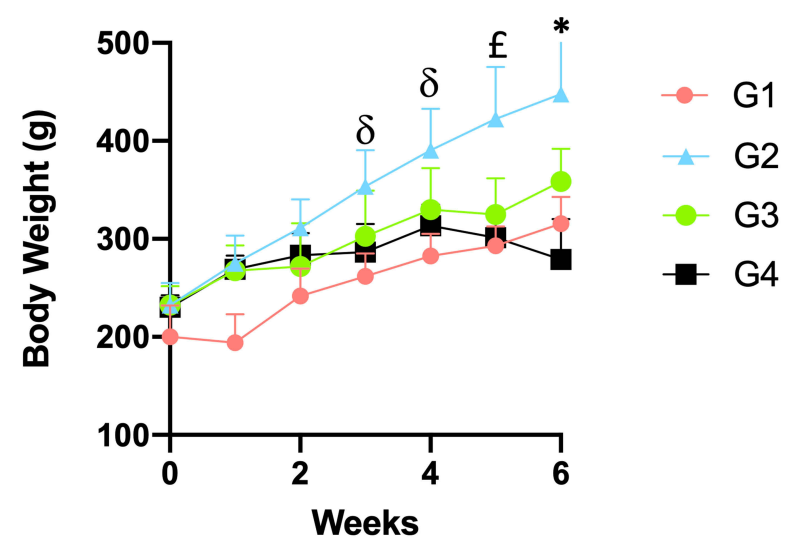

E

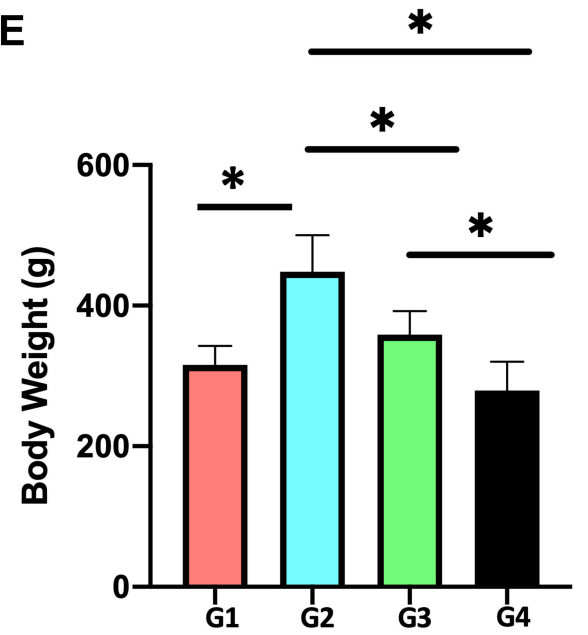

Figure 2 Effect of high-fat diet/disulfiram on rats at week 6. Dorsal view of: (A) GI (SD) vs G2 (HFD), (B) G3 (HFD + 50mg DSF started at W0) vs G2 (HFD), (C) G4 (HFD $+200 \mathrm{mg}$ DSF started at W0) vs G2 (HFD). (D) Body weight of GI-G4 over the 6 weeks of the study. (E) Body weight of GI-G4 at week 6 . Data are presented as mean \pm

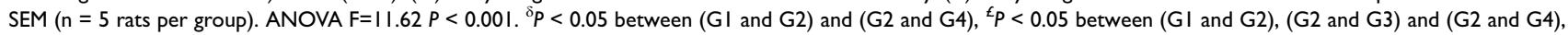
$* P<0.05$ between (GI and $\mathrm{G} 2),(\mathrm{G} 2$ and $\mathrm{G} 3),(\mathrm{G} 2$ and $\mathrm{G} 4)$ and $(\mathrm{G} 3$ and $\mathrm{G} 4)$.

weight their counterparts receiving standard diet nonsignificantly increased by $2.47 \pm 6.84 \%$ (from $315.6 \pm 27.15$ to $323.4 \pm 35.14 \mathrm{~g})(P=0.317)$ over the same period of time. Meanwhile, rats fed with HFD and received $50 \mathrm{mg} / \mathrm{kg} / \mathrm{day}$ of DSF, G6, lost $16.74 \pm 8.61 \%$ (from $414.2 \pm 68.54 \mathrm{~g}$ to $351.3 \pm 92.60 \mathrm{~g})(P=0.009)$ from their weight during the same time interval. Moreover, $200 \mathrm{mg} / \mathrm{kg} / \mathrm{day}$ of DSF caused a body weight reduction of $23.9 \pm 3.93 \%$ (from
$417.4 \pm 21.65 \mathrm{~g}$ to $321.8 \pm 8.18 \mathrm{~g})(P=0.003)$ in $\mathrm{G} 7$ over the same period, Figure 3.

\section{Comparison Between Groups at Week Six and Week 9}

There was a statistically significant difference between the four groups after six weeks of intervention using the one-way ANOVA $(\mathrm{F}(3,18)=11.620, \mathrm{P}<0.001)$. Levene's test was 

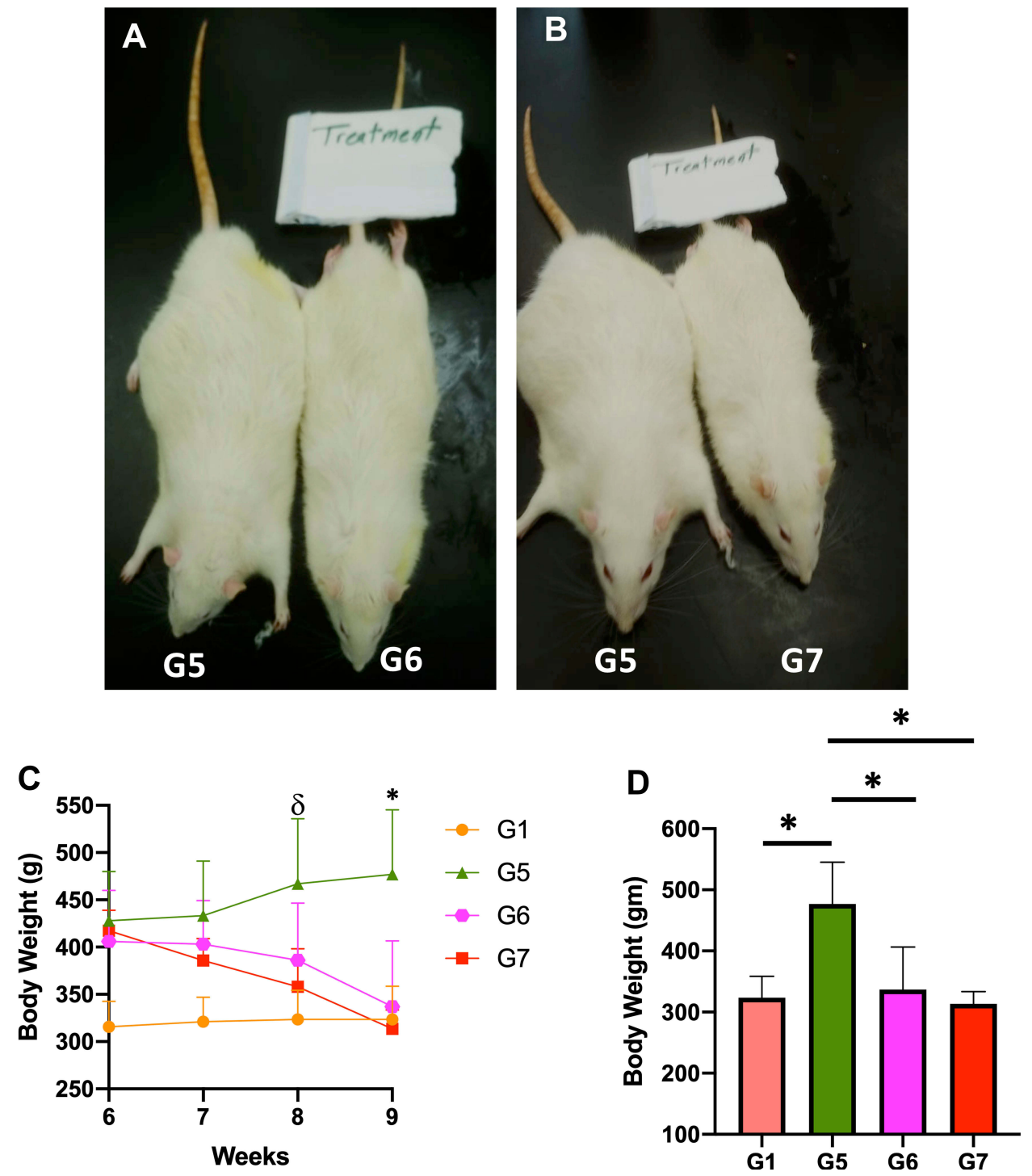

Figure 3 Effect of disulfiram on rats at week 9. Dorsal view of: (A) G5 (HFD) vs G6 (HFD + 50mg DSF started at W6), (B) G5 (HFD) vs G7 (HFD + 200mg DSF started at W6). (C) Body weight of GI, G5-G7 over the 3 weeks of the study. (D) Body weight of GI, G5-G at week 9. Data are presented as mean \pm SEM ( $n=5$ rats per group). ANOVA $F=7.779, P=0.02 .{ }^{\delta} P<0.05$ between (GI and G5) and (G5 and G7), $* P<0.05$ between (GI and G5), (G5 and G6), and (G5 and G7).

not significant $(\mathrm{P}=0.146)$. For post hoc analysis, the results of the Tukey HSD test for multiple comparison showed a statistically significance difference between G1 and G2 $(\mathrm{P}=0.001)$. Additionally, there was no statistically significant difference neither between G1 and G3 $(P=0.402)$, nor between $\mathrm{G} 1$ and $\mathrm{G} 4(\mathrm{P}=0.490)$. However, there was a statistically significant difference between G3 and G4 $(\mathrm{P}=0.042)$, Figure 2E.

After redistribution of the HFD groups at week six, there was a statistically significant difference between the four groups after three weeks of intervention using the one-way ANOVA $(\mathrm{F}(3,18)=7.779, P=0.02)$. Levene's test was not significant $(P=0.095)$. For post hoc analysis, the results of the Tukey HSD test for multiple comparison showed a statistically significance difference between $\mathrm{G} 1$ and G5 $(P=0.005)$ but neither between G1 and G6 $(P=0.814)$, nor between G1 with G7 $(P=0.987)$. On the other hand, there was a statistically significant difference between G5 and G6 $(P=0.025)$, and between G5 and G7 $(P=0.003)$. Furthermore, there was no statistically significant difference between the $50 \mathrm{mg} \mathrm{G} 5$ and G7 $(P=0.627)$, Figure 3D.

\section{Food and Water Intake}

Food and water intakes were calculated for three separate days in the middle of the study. DSF administration had no statistically significant effect on the food intake of the treated animals at either dose. However, DSF significantly 
Table I Food and Water Consumption

\begin{tabular}{|c|c|c|c|c|c|c|c|}
\hline & \multicolumn{4}{|c|}{ Groups Mean Values } & \multirow[b]{2}{*}{ F value } & \multirow[b]{2}{*}{$P$ value } & \multirow{2}{*}{$\begin{array}{l}\text { ANOVA } \\
\text { Multiple Comparison }\end{array}$} \\
\hline & G I & G2 & G3 & G4 & & & \\
\hline Food g/I00g BW/Day & $8.49 \pm 0.373$ & $5.75 \pm 0.522$ & $6.08 \pm 0.836$ & $4.11 \pm 0.389$ & $F(3,8)=\mid 0.31$ & 0.004 & $\begin{array}{l}\text { GI, G3; P }=0.04 \\
\text { GI, G4; }=0.003\end{array}$ \\
\hline Water $\mathrm{mL} / 100 \mathrm{~g}$ BW/Day & 12.58 & 5.95 & 8.20 & 7.31 & $F(3,8)=41.55$ & $<0.001$ & $\begin{array}{l}\text { GI, G2; } P<0.00 I \\
\text { GI, G3; } P<0.00 I \\
\text { GI, G4; } P<0.001 \\
\text { G2, G3; P=0.03 } \\
\text { G2, G4; } P=0.021\end{array}$ \\
\hline
\end{tabular}

Note: Data are presented as mean $\pm \operatorname{SEM}(n=5$ rats per group).

increased the water consumption of treated rats compared to their counterparts receiving HFD only, Table 1.

\section{Glycemic Response}

OGTT was performed at week six to evaluate the effect of DSF on the glycemic response in HFD-fed rats, Figure 4. The total AUC of the glycemic response was calculated for groups G1-G4. The DSF decreased the AUC at both doses. However, this reduction was not statistically significant, Table 2.

\section{Discussion}

Retinoids and the enzymes controlling their metabolism form a complex system that controls important biological processes, such as fuel metabolism and adipogenesis. ${ }^{23,24,31}$

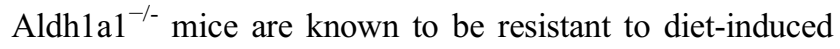
obesity, and they show better insulin sensitivity than their wildtype counterparts. ${ }^{23,31}$ Disulfiram is a known inhibitor of aldehyde dehydrogenases. ${ }^{15}$ It is an FDA-approved drug for treating chronic alcoholism. Disulfiram is considered a safe, well tolerated drug. ${ }^{32}$ A single oral dose of $6 \mathrm{~g}$ or daily doses of up to $0.75 \mathrm{~g}$ administered for months are generally

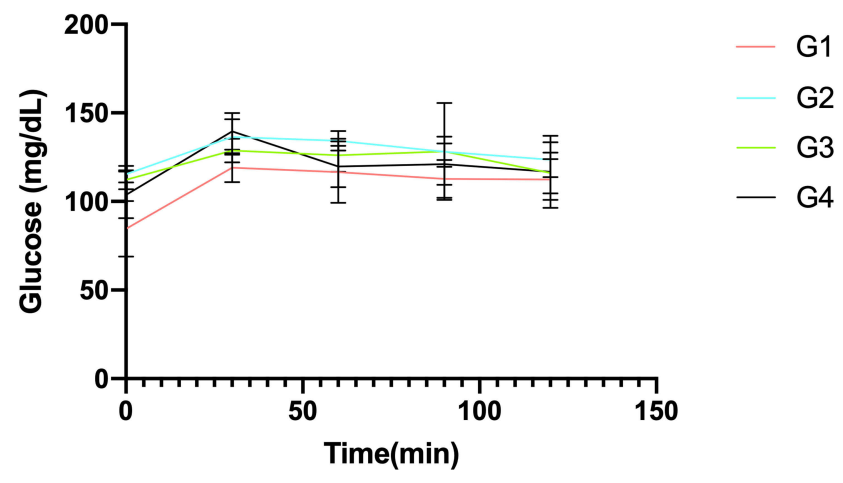

Figure 4 Glycaemic response during oral glucose tolerance test. Data are presented as mean $\pm \operatorname{SEM}(n=5$ rats per group).
Table 2 Glycemic Response. AUC for Oral Glucose Tolerance Test

\begin{tabular}{|l|l|l|l|l|}
\hline Groups & GI & G2 & G3 & G4 \\
\hline Total Area & 13,407 & 15,543 & $14,9 \mid 3$ & $|4,72|$ \\
Std. Error & 549.2 & 344.9 & 658.0 & 552.2 \\
$95 \%$ & $12,33 \mid$ to & 14,867 to & 13,623 to & 13,639 to \\
$\begin{array}{l}\text { Confidence } \\
\text { Interval }\end{array}$ & 14,483 & 16,219 & 16,203 & 15,803 \\
\hline
\end{tabular}

tolerated by human adults without symptoms. ${ }^{33,34}$ Disulfiram is also characterized by a high oral $\mathrm{LD}_{50}$ dose of up to $8.6 \mathrm{~g} / \mathrm{kg}$ in rats. ${ }^{35}$ Indeed, disulfiram is a potent inhibitor of both isoforms of aldehyde dehydrogenase Ald1a1 and Aldh2. But since Aldh1a1 has bigger substrate entrance tunnel than Aldh2, disulfiram, a rather large hydrophobic compound, has a higher affinity to Aldh $1 \mathrm{a} 1 .^{20}$ In this work, we investigated the potential use of disulfiram as a treatment for obesity.

Our results showed that despite the fact that DSF had no significant effect on food intake, it considerably limited the body weight gain of treated animals caused by an HFD. When administered at a moderate dose of $50 \mathrm{mg} /$ $\mathrm{kg}$ /day to rats along with an HFD, DSF completely cancelled the obesogenic effect of the diet after six weeks of treatment. HFD-fed rats treated at higher doses of DSF, $200 \mathrm{mg} / \mathrm{kg} /$ day, showed a strong resistance to body weight increase. They gained less weight compared not only to their counterparts receiving HFD but also to those on a standard diet.

DSF also considerably decreased the body weight of obese animals at both doses of 50 and $200 \mathrm{mg} / \mathrm{kg} /$ day. After three weeks of DSF treatment, obese rats lost up to $24 \%$ of their weight, thus restoring a body weight matching that of those who received a standard diet. 
All in all, disulfiram, an FDA-approved drug, showed promising anti-obesity activity on high-fat diet-fed rats at both tried doses. These findings suggest disulfiram as a potential treatment for obesity. Future studies should focus on the molecular mechanisms of disulfiram. Clinical trials on healthy obese adults could also be envisaged.

\section{Acknowledgment}

The authors would like to acknowledge the financial support provided by King Abdulaziz City for Science and Technology (KACST), Grant No. 2-17-03-007-0010. The authors are grateful to Dr Mahmoud Elrggal from Umm AlQura University and to Dr Ahmed Alaskar from King Abdullah International Medical Research Center for helpful discussion.

\section{Disclosure}

The authors report no conflicts of interest in this work.

\section{References}

1. Masters RK, Reither EN, Powers DA, Yang YC, Burger AE, Link BG. The impact of obesity on US mortality levels: the importance of age and cohort factors in population estimates. Am J Public Health. 2013;103(10):1895-1901. doi:10.2105/AJPH.2013.301379

2. World Health Organization. Obesity and overweight fact sheet. Available from: http://www.who.int/mediacentre/factsheets/fs311/en/ index.html. Accessed May 17, 2017.

3. Haslam DW, James WP. Obesity. Lancet. 2005;366 (9492):1197-1209. doi:10.1016/S0140-6736(05)67483-1

4. Kopelman PG. Obesity as a medical problem. Nature. 2000;404 (6778):635-643. doi:10.1038/35007508

5. Dodson MV, Boudina S, Albrecht E, et al. A long journey to effective obesity treatments: is there light at the end of the tunnel? Exp Biol Med. 2013;238(5):491-501. doi:10.1177/1535370213477603

6. Frood S, Johnston LM, Matteson CL, Finegood DT. Obesity, complexity, and the role of the health system. Curr Obes Rep. 2013;2 (4):320-326. doi:10.1007/s13679-013-0072-9

7. Omran Z. Obesity: current treatment and future horizons. Mini Rev Med Chem. 2017;17(1):51-61. doi:10.2174/1389557516666160617100328

8. Belviq, Belviq XR (lorcaserin) by Eisai: drug Safety Communication - FDA Requests Withdrawal of Weight-Loss Drug. Available from: https://www.fda.gov/safety/medical-product-safety-information/bel viq-belviq-xr-lorcaserin-eisai-drug-safety-communication-fdarequests-withdrawal-weight-loss-drug. Acessed Mar 16, 2020.

9. Roberts CA, Christiansen P, Halford JCG. Pharmaceutical approaches to weight management: behavioural mechanisms of action. Curr Opin Physiol. 2019;12:26-32. doi:10.1016/j.cophys.2019.04.017

10. Pushpakom S, Iorio F, Eyers PA, et al. Drug repurposing: progress, challenges and recommendations. Nat Rev Drug Discov. 2019;18 (1):41-58. doi:10.1038/nrd.2018.168

11. Ashburn TT, Thor KB. Drug repositioning: identifying and developing new uses for existing drugs. Nat Rev Drug Discov. 2004;3 (8):673-683. doi:10.1038/nrd1468

12. Nosengo N. Can you teach old drugs new tricks? Nature. 2016;534 (7607):314-316. doi:10.1038/534314a
13. Cao B, Wang Y, Wen D, et al. A trial of lopinavir-ritonavir in adults hospitalized with severe Covid-19. N Engl J Med. 2020. doi:10.1056/ NEJMoa2001282

14. Gautret P, Lagier JC, Parola P. et al. Hydroxychloroquine and azithromycin as a treatment of COVID-19: results of an open-label non-randomized clinical trial. Int $J$ Antimicrob Agents. 2020: 105949. doi:10.1016/j.jjantimicag.2020.105949

15. Bell RG, Smith HW. Preliminary report on clinical trials of antabuse. Can Med Assoc J. 1949;60(3):286-288.

16. Yang Q, Yao Y, Li K, et al. An updated review on disulfiram: molecular targets and strategies for cancer treatment. Curr Pharm Des. 2019;25(30):3248-3256. doi:10.2174/1381612825666190816233755

17. Lee SA, Elliott JH, McMahon J, et al. Population pharmacokinetics and pharmacodynamics of disulfiram on inducing latent HIV-1 transcription in a Phase IIb trial. Clin Pharmacol Ther. 2019;105 (3):692-702. doi: $10.1002 /$ cpt. 1220

18. Rasmussen TA, Sogaard OS. Clinical Interventions in HIV cure research. Adv Exp Med Biol. 2018;1075:285-318.

19. Liegner KB. Disulfiram (Tetraethylthiuram Disulfide) in the treatment of lyme disease and babesiosis: report of experience in three cases. Antibiotics (Basel). 2019;8:2.

20. Moore SA, Baker HM, Blythe TJ, Kitson KE, Kitson TM, Baker EN. Sheep liver cytosolic aldehyde dehydrogenase: the structure reveals the basis for the retinal specificity of class 1 aldehyde dehydrogenases. Structure. 1998;6(12):1541-1551. doi:10.1016/S0969-2126(98)00152-X

21. Ross AC. Overview of retinoid metabolism. J Nutr. 1993;123(2 Suppl):346-350. doi:10.1093/jn/123.suppl_2.346

22. Duester G, Mic FA, Molotkov A. Cytosolic retinoid dehydrogenases govern ubiquitous metabolism of retinol to retinaldehyde followed by tissue-specific metabolism to retinoic acid. Chem Biol Interact. 2003;143-144:201-210. doi:10.1016/S0009-2797(02)00204-1

23. Kiefer FW, Vernochet C, O'Brien P, et al. Retinaldehyde dehydrogenase 1 regulates a thermogenic program in white adipose tissue. Nat Med. 2012;18(6):918-925. doi:10.1038/nm.2757

24. Ziouzenkova O, Orasanu G, Sharlach M, et al. Retinaldehyde represses adipogenesis and diet-induced obesity. Nat Med. 2007;13 (6):695-702. doi:10.1038/nm1587

25. Yang F, Zhang X, Maiseyeu A, et al. The prolonged survival of fibroblasts with forced lipid catabolism in visceral fat following encapsulation in alginate-poly-L-lysine. Biomaterials. 2012;33 (22):5638-5649. doi:10.1016/j.biomaterials.2012.04.035

26. Xu L, Shen Q, Mao Z, Lee LJ, Ziouzenkova O. Encapsulation thermogenic preadipocytes for transplantation into adipose tissue depots. J Vis Exp. 2015;100:e52806.

27. Gilor C, Yang K, Lee A, et al. Thermogenic crosstalk occurs between adipocytes from different species. Sci Rep. 2019;9(1):15177. doi:10.1038/s41598-019-50628-9

28. Fan X, Molotkov A, Manabe S, et al. Targeted disruption of Aldh1a1 (Raldh1) provides evidence for a complex mechanism of retinoic acid synthesis in the developing retina. Mol Cell Biol. 2003;23 (13):4637-4648. doi:10.1128/MCB.23.13.4637-4648.2003

29. Lin YS, Han CH, Lin SY, Hou WC. Synthesized peptides from yam dioscorin hydrolysis in silico exhibit dipeptidyl peptidase-IV inhibitory activities and oral glucose tolerance improvements in normal mice. J Agric Food Chem. 2016;64(33):6451-6458. doi:10.1021/acs. jafc.6b02403

30. Marques C, Meireles M, Norberto S, et al. High-fat diet-induced obesity Rat model: a comparison between Wistar and Sprague-Dawley Rat. Adipocyte. 2016;5(1):11-21. doi:10.1080/ 21623945.2015.1061723

31. Kiefer FW, Orasanu G, Nallamshetty S, et al. Retinaldehyde dehydrogenase 1 coordinates hepatic gluconeogenesis and lipid metabolism. Endocrinology. 2012;153(7):3089-3099. doi:10.1210/en.2011-2104

32. Silver DF, Ewing JA, Rouse BA, Mueller RA. Responses to Disulfiram in healthy young men; a double-blind study. J Stud Alcohol. 1979;40(11):1003-1013. doi:10.15288/jsa.1979.40.1003 
33. Martensen-Larsen O. Psychotic phenomena provoked by tetraethylthiuram disulfide. $Q$ J Stud Alcohol. 1951;12(2): 206-216.

34. Disulfiram [MAK Value Documentation, 1993]. The MAKCollection for Occupational Health and Safety. 166-180.
35. Sauna ZE, Peng XH, Nandigama K, Tekle S, Ambudkar SV. The molecular basis of the action of disulfiram as a modulator of the multidrug resistance-linked ATP binding cassette transporters MDR1 (ABCB1) and MRP1 (ABCC1). Mol Pharmacol. 2004;65(3):6 75-684. doi:10.1124/mol.65.3.675

\section{Publish your work in this journal}

Diabetes, Metabolic Syndrome and Obesity: Targets and Therapy is an international, peer-reviewed open-access journal committed to the rapid publication of the latest laboratory and clinical findings in the fields of diabetes, metabolic syndrome and obesity research. Original research, review, case reports, hypothesis formation, expert opinion and commentaries are all considered for publication. The manuscript management system is completely online and includes a very quick and fair peer-review system, which is all easy to use. Visit http://www.dovepress.com/testimonials.php to read real quotes from published authors. 